\title{
Grammar: Relevance-Theoretic Concerns
}

\author{
Francisco Yus Ramos \\ Universidad de Alicante
}

\begin{abstract}
Relevance theory (Sperber and Wilson, 1986) provides an interesting cognitive framework for the study of how interpretation takes place in face-to-face interaction. However, the applicability of this theory extends beyond conversation and this article also outlines how grammar can be analysed from a relevance-theoretic perspective. The purpose of this article is to provide a review of different studies of grammatical aspects of sentences which overlap with more traditional approaches in order to obtain a more accurate and context-centred picture of grammar. The extensive bibliography provided will surely be useful as a starting point for analysts interested in grammar from a pragmatic perspective.
\end{abstract}

\section{Relevance theory: a brief overview}

Sperber and Wilson (1986) developed a cognitive approach to interpretation from their initial proposal of the unification of Grice's (1975) classic maxims in a single principle of relevance. This cognitive theory (RT henceforth) centres around the importance of intention and inference in every communicative act. In their approach to intention, Sperber and Wilson (S\&W henceforth) come close to the ideas of Grice (1975) and Strawson (1964), among others, about meaning and communication centred on the addressee's recognition of the addresser's informative intention, with the help of the parallel recognition of the communicative intention underlying that utterance (or stimulus, as S\&W prefer to call it). The explicit manifestation of one's intention that something becomes manifest for the hearer becomes an ostensive communicative action. Ostensive stimuli 
must satisfy three requirements: (S\&W 1986: 153-154): (a) attract the audience's attention; (b) focus it on the communicator's intentions; and (c) reveal the communicator's intentions.

As far as inference is concerned, S\&W (1987: 697) think that inference can fill the gap between the semantic representation of utterances and the message that each utterance eventually communicates. They emphasize the role of the communicators in manifesting both their communicative and informative intention with the utterance, while the hearer tries to work out different hypotheses as to what the correct interpretation is. With this pragmatic approach, S\&W avoid traditional views that explained communication as a simple, straightforward decoding of the messages encoded by the communicator.

In their interpretive model, $S \& W$ also stress the importance of deduction, which is the result of bringing together new information $\{P\}$ and old information $\{C\}$ previously stored in the hearer's mind. S\&W name this cognitive operation contextualization (S\&W 1986: 108). This contextualization can produce contextual effects. A contextual effect is generated when the context is modified in a certain way by the new information. This modification of context results in the strengthening or weakening of former assumptions.

All this theoretical background is the base on which $S \& W$ place the central proposal of their theory, which can be summarised in four statements (Wilson 1994: 44): (a) every utterance has a variety of possible interpretations, all compatible with the information that is linguistically encoded; (b) not all these interpretations occur to the hearer simultaneously, some of them take more effort to think up; (c) hearers are equipped with a single, general criterion for evaluating interpretations; and (d) this criterion is powerful enough to exclude all but at most a single interpretation, so that having found an interpretation that fits the criterion, the hearer looks no further.

In a nutshell, for S\&W interpretation depends on the addressee's choice of one interpretive hypothesis (among many other possible hypotheses) that is consistent with the addresser's communicative intention. This cognitive activity has to do with an enrichment of the logical form of the utterance in order to get a propositional form which, depending on the role of context, can match the intended interpretation (at the level of explicatures) or further contextual accesses may be needed in order to reach the intended implicature of the utterance (taken here in a slightly different sense from Grice's).

However, processing the information underlying ostensive communication is subject to risk and effort: the risk of not being completely sure of what assumption, in a range of multiple other assumptions that every communicative activity can produce in the hearer, is the one that the speaker wants the hearer to process (Blakemore 1992: 21); and the effort of choosing one proposition and processing it, after having compared it to previously stored information. This is why every ostensive communicative activity carries the guarantee of its relevance, that is, the speaker is aware of the cognitive effort that the hearer has to make, and presupposes that despite this, the benefits of the eventual interpretation of the utterance are worth this effort.

From this perspective, we can deduce that different degrees of relevance are generated from the fact that every information-processing activity demands a certain amount of mental effort from the hearer, and the bigger this effort, the less relevant. In conclusion, the definition of relevance can be formulated roughly with two preliminary conditions (S\&W 1986: 125): 
Condition 1: an assumption is relevant in a context to the extent that its contextual effects in this context are large.

Condition 2: an assumption is relevant in a context to the extent that the effort required to process it in this context is small.

When these two conditions are satisfied, the utterance is consistent with the principle of relevance. If the hearer finds a (first) interpretation that satisfies these conditions, the process of interpretation will stop at this point.

\section{Relevance theory and grammar: A complementation of traditional views}

$S \& W ' s$ proposal of a balance between interest and effort, which guides hearers in the selection of a (first and only) appropriate interpretation of utterances, together with the importance of S\&W's proposal of an enrichment of the logical form of utterances in the search for this interpretation, underlie most of the research on grammar under an RT framework. In short, grammatical aspects are no longer intrinsic and relatively stable features of language, nor are grammatical attributes a mere list of choices in hypothetical contexts supplied by the grammarian. Instead, a pragmatic and consequently contextcentred view of grammar is proposed in which grammatical attributes constrain (or not) the choice of a right (i.e. intended) interpretation. The addressee's ability to access the adequate context in which the utterance can be optimally processed also plays an important part in the outcome of interpretation (Haegeman, 1987). In this sense, the grammatical organization of utterances has an important role throughout this cognitive contextualisation, since it often imposes constraints upon the range of possible interpretations of the utterance and thus reduces the effort required to select the intended interpretation (more on this below).

\section{Studies on grammar from a relevance-theoretic perspective}

Below there is a short review of studies which, one way or another, analyse grammatical aspects of language using RT as the main theoretical framework.

(a) Undoubtedly, one of the most important contributions of RT to the study of grammar has resulted from the work by Blakemore (1987a, 1987b, 1988a, 1988b, 1989, 1990; Brockway, 1981, 1982) on connectives, which has led to a real flow of studies in the same direction (see Ariel, 1988; Blass, 1988, 1990, 1993; Gutt, 1988; Haegeman, 1993; Higashimori, 1992a, 1992b, 1994, 1995, 1997; Itani, 1992; Jucker, 1993; Watts, 1986; Moeschler, 1989a, 1989b, 1993a; Rouchota, 1990, 1996; Smith and Smith, 1988; Unger, forthcoming; W\&S, 1993; Fretheim, 1997; Iten, 1997; Takeuchi, 1997). Going beyond the traditional approach which tends to a primary distinction between same-level relationship of elements (coordination, parataxis) and a hierarchy-based one (subordination, hypotaxis), a certain class of connectives including after all, so, but, 
whereas, etc. are regarded as constraints on relevance, that is, as guidelines for the correct comprehension of the compound sentence, since they reduce the effort needed to access the correct (i.e. intended) interpretation. In Blakemore's (1987b) words,

their sole function is to guide the interpretation process by specifying certain properties of context and contextual effects. In a relevance-based framework, where the aim is to minimise processing costs, the use of such expressions is to be expected. (77)

Consequently, from this perspective, connectives are used in order to make implicit coherence relations explicit (Rouchota, 1996: 201), and hence to establish a safe guideline for the interpretation of utterances containing them.

For instance the connective but has two basic meanings: "denial of expectation" and “contradiction." In a sentence such as (1) below (Rouchota, 1996: 201),

(1) He votes Tory but I trust him.

by using but the speaker indicates that the proposition it introduces is relevant as a denial of the expectation created by the proposition expressed in the first clause.

Also, the connective and is not simply a (neutral) equivalent to the logical conjunction operator, and pragmatics has to be able to account to asymmetrical examples such as (2a-c) below, in which there is more to the meaning of the sentence than the mere addition of the meaning of the two clauses (Carston, 1993):

(2) (a) He handed her the scalpel and she made the incision.

(b) We went to Paris and I visited several museums.

(c) I watched TV and I fell asleep.

From a pragmatic point of view, the relationship between the clauses in the above examples is determined via inference and the individual's assumptions, overlapping with the parallel decoding of the semantic content of the clauses. For example, for (2a), the interpretation (3a) is much more likely to be picked up as the intended interpretation than (3b), even though both are, in theory, possible (Carston, ibid:: 29):

(3) (a) He handed her the scalpel and a second or two later she made the incision with that scalpel.

(b) He handed her the scalpel and simultaneously she made the incision with her pocketknife.

Underlying this approach to connectives, there is a basic dichotomy in RT-related pragmatic analysis: conceptual vs procedural meanings. In a nutshell, there are two types of meaning which have been developed mainly in two areas: linguistic (having to do with truth-conditions) and cognitive (linguistic decoding provides input to the inferential phase of comprehension). This second area confirms the existence of conceptual and procedural information as used by Blakemore and her followers. In W\&S's (1993) words: 
Inferential comprehension involves the construction and manipulation of conceptual representations; linguistic decoding feeds inferential comprehension; linguistic constructions might therefore be expected to encode two basic types of information: concepts or conceptual representations on the one hand, and procedures for manipulating them on the other. (10)

Blakemore applies this hypothesis to connectives, which should not be seen as encoding concepts, but as procedural devices which constrain the inferential phase by indicating the kind of cognitive process that the hearer should go through (hence reducing the eventual overall effort).

(b) Smith and Smith (1988), Foster-Cohen (1997) and Noh (1996) have applied RT to conditionals. In general, there is some discussion on whether conditionals are similar to the logical "implication" or closer to non-truth-functional words relating the antecedent and the consequent in the sentence. The gap between these semantic vs pragmatic uses of conditionals can be filled using an RT framework. Smith and Smith, for instance, suggest that if is semantically equivalent to the logical implication ' $\rightarrow$ ', and that the behaviour of both factual and counterfactual conditionals can be explained in contextual, relevancetheoretic terms. For example:

(4) (a) If you are confident enough, bet your whole salary on that horse.

(b) If I ask you politely, will you post the letter?

(c) If you are hungry, there is a flan in the fridge.

In these sentences the hearer has to recover the propositional form of the sentence (via enrichment of the logical form) and integrate it into a description according to the imperative (the speaker is telling the speaker to $P$, as in (4a)), or an interrogative connotation, as in (4b), and in both cases there is a guarantee of relevance for the speaker and/or hearer. For (4c), Smith and Smith propose the following RT-related explanation:

the antecedent specifies a state of affairs which, as usual, provides a relevant context for the consequent. Given the Principle of Relevance, this in turn forces the listener to make certain additional assumptions: specifically, that he can infer from the guaranteed relevance of the consequent that the flan in the fridge is available for him. Given the easily accessible information that hunger is undesirable, that eating alleviates hunger and that flans are for eating, the force of the whole conditional is accounted for naturally. (335)

$\mathrm{RT}$ is also useful for conditional sentences in which the antecedent contradicts some assumption(s) which form(s) part of the context (see Smith and Smith, ibid. 342f).

(c) Carston (1994), Carston and Noh (1995), and Yoshimura (1992, 1993) analyse negation from an RT perspective. Carston and Noh's $(1994,1995)$ object of analysis is a certain variety called metalinguistic negation, in which the speaker provides an objection to the proposition within the scope of negation, as in (5a-b) below: 
(5) (a) He isn't neurotic or paranoid; he's both.

(b) She's not my mother; she's my female progenitor.

What is at stake here is, again, the truth-functionality of negation. As Carston (1994) points out, it is usually assumed that since the more prototypical kind of negation deals with truth-conditional content, this variety of negation used as objection does not. As Carston concludes, under RT this variety of negation need not imply a (semantic or pragmatic) contradiction of the second clause with respect to the first one. Rather, the hearer often reaches the end of the first clause with an adequate enrichment of the kind of pragmatic relation linking the two elements in the sentence, so that the follow-up clause does not entail a contradiction, but an overall meaningful sense.

(d) Several analysts have studied modals and modality using a relevance-theoretic approach (Berbeira Gardón, 1993, 1996a, 1996b, 1997, forthcoming; Groefsema, 1995; Klinge, 1993; Carretero Lapeyre, 1997; Nicolle, 1997a; Papafragou, 1997). They attempt to provide a cognitive explanation for the various senses in which modals can be used in similar contexts. For example, may has both epistemic and deontic interpretations of (6a) in $(6 b)$ and $(6 c)$ respectively:

(6) (a) She may do the examination tomorrow.

(b) It is possible that she will do the examination tomorrow.

(c) She is permitted to do the examination tomorrow.

Instead of simply claiming that modal auxiliaries are ambiguous, under RT they are considered to have a basic meaning, and the different interpretations which they can acquire are dependent on contextual attributes. In other words, there is a basic propositional meaning which is later enriched to yield a propositional form with a contextrelated (epistemic/deontic) meaning (Berbeira Gardón, 1993: 58). Groefsema (1995: 61) goes on to say that "the basic meanings of can, may, must and should express relations between the proposition expressed by the rest of an utterance containing them and a set of 'background' assumptions, while putting constraints on what sets of assumptions are recovered during the interpretation process." Klinge (1993), on the other hand, differs slightly from this proposal, since he claims that the modals' contribution to the interpretation of an utterance is to provide a relation between the proposition expressed (situation expression in his terminology) and a state of affairs (or world situation).

(e) Ifantidou-Trouki (1993), Watts (1988), and Bertuccelli-Papi (1996), among others, have studied adverbs and adverbials under RT. Ifantidou-Trouki deals with four types of adverbials: illocutionary (frankly, confidentially, honestly...), attitudinal (unfortunately, happily, sadly...), evidential (evidently, obviously...) and hearsay (allegedly, reportedly). They are usually regarded as non-truth-conditional, that is, as not contributing to the proposition expressed by the utterance, but as indicators of the type of speech act performed with the utterance. The RT-based analysis proves that in reality these kinds of adverbials are very different from each other in their use and non-truth-functionality. As 
it turns out, not all adverbs have a procedural role in the utterances where they occur, helping the hearer in their processing, but also encode conceptual representations, even though in two types of adverbials (illocutionary, attitudinal) their role is not as essential as to contribute to the truth conditions of the utterance as a whole.

(f) Clark (1993a, 1993b), Lunn (1989), Rouchota (1994a, 1994b) and W\&S (1988) study moods such as subjunctive and imperative. Clark's concern is pseudo-imperatives. These include verbs used with a covert conditional meaning, as in (7a-d) and also the kindof-imperative sense of let's in (7e):

(7) (a) Wash the car and I'll buy you an ice-cream.

(b) Leave the house or I'll call the police.

(c) Come one step closer and I'll shoot.

(d) Turn on the radio and you'll hear the news about the murder.

(e) Let's go to the cinema tonight.

Clark claims that RT can explain their grammatical behaviour without any extra syntactic or semantic theoretical machinery. Again, the semantic content of the utterance has to be combined with contextual information in order to access its intended interpretation or, in this case, its eventual pseudo-imperative force. For instance, the explanation of the "conditional" interpretation of sentences such as (7a-d) is entirely pragmatic, and can be explained in relevance-theoretic terms: "in each case the hearer has to make some assumption about how desirable the state of affairs is thought to be and from whose point of view it is thought to be desirable; in making these assumptions he is guided by contextual factors and considerations of optimal relevance" (Clark, 1993a: 82; 1993b: 174).

(g) Jucker (1992) unifies the different senses of the definite article proposed by Quirk et al.(1985) under RT. In general, the definite article makes reference to some identifiable person, object, concept, etc. which acquires prominence in a given context, or it is used in anaphoric/cataphoric reference to another word in the sentence or the text concerned, among other uses. In general, though, and as S\&W acknowledge, hearers can only make non-demonstrative assumptions about their interlocutors' own assumptions, and successful communication depends on these assumptions being accurate. This, when applied to noun phrases, implies that speakers continuously make assumptions about whether their interlocutors will manage to identify the intended referent of the noun phrase or not, with the following sub-assumption:

The referent of the expression which contains a definite article is uniquely identifiable at the particular point of the discourse at which the expression occurs. (128)

which is part of the meaning of the definite article and therefore underlies most of the uses proposed by Quirk $e t$ al. (1985): "the various categorisations of uses of the definite article that have been proposed by grammarians in essence try to compartmentalise the bases on 
which speakers assume that their addressees will be able to pick up the correct referent" (ibid., 130).

See Breheny (1997) for another relevance-theoretic analysis of definites.

(h) Smith (1990), Haegeman (1989) and Moeschler (1993b) choose tense as the focus of grammatical analysis under RT. Smith's hypothesis is that RT provides an ideal framework to avoid the ambiguities that arise in logical descriptions of tense. Indeed, in $\mathrm{RT}$ it is not enough to say that the past tense provides a temporal reference prior to the moment of speaking. Instead, the hearer is expected to "narrow the reference down to some more specific interval, so that the utterance can be constructed as expressing an optimally relevant proposition; that is, so that it can interact with accessible contextual assumptions to give rise to a range of effects" (Smith, 1990: 85). Smith goes on to apply RT to the sequentiality of the narrative past, in sentences such as the following:

(8) John entered the office. The president walked over to him.

in which the information provided by the second clause is interpreted as preceded in time by the one provided by the first clause. Following Carston (1988), Smith concludes that this phenomenon is part of 'reference assignment' and consequently part of the propositional enrichment to yield an explicature of the sentence.

Haegeman's analysis focuses on the difference between going to and will, in an attempt to overcome the intuitive distinction of these auxiliaries in examples such as $(9 a-b)$ below:

(9) (a) I will/shall leave next week.

(b) I'm going to leave next week.

Her claim is that at the level of sentence meaning, the meaning of both auxiliaries is equivalent, and that the difference is to be found in the constraints that they impose on the processing in context of the utterance in which they occur. In her study she applies the conceptual/procedural distinction outlined above to conclude that

Be going to... imposes a constraint on the processing of the proposition with which it is associated. It signals that this proposition is relevant in a context including at least some present tense propositions, or, in other words, it guarantees a contextual effect if the utterance is processed against a present context. Will, on the other hand, signals that the hearer should extend the immediately accessible (present) context for the processing of the proposition and should process the utterance against future propositions. (305)

This proposal is then applied to these auxiliaries in combination with ellipsis and conditionals, among other relevant aspects of their use. For discussion, see also Nicolle (1997b).

(i) Žegarac $(1889,1990,1993)$ turns to aspect under a relevance-theoretic approach. Starting off with a traditional classification of aspect and situation types, he concludes that 
under RT these traditional labels seem problematic. For example, in the case of stative verbs, which cannot be used in the progressive aspect, many instances are found which are clear exceptions to this rule (1989: 24, 1990: 127):

(10) (a) Peter is being polite.

(b) Mary is loving the fruit salad.

In this case, the hearer realises that (10a) and (10b) are not intended to be interpreted literally, and starts looking for assumptions about what the speaker might have intended to convey.

Basically, the heart of the matter lies in the quality of the encyclopaedic entries for the verbs concerned and the hearer's accessibility to contexts in which the stative meaning of the verbs is eventually created. Some examples by Žegarac (1990: 129) are particularly illustrative:

(11) (a) John doesn't feel well.

(b) John isn't feeling well.

(12) (a) The baby resembles her mother.

(b) The baby is resembling her mother more and more.

(c) ?? The baby is resembling her mother.

(13) (a) Antoinette understands Russian.

(b) Antoinette is understanding Russian better and better.

(c) ?? Antoinette is understanding Russian.

Quoting Žegarac,

The meaning of the progressive is to be defined in terms of reference to instantiation(s) of the property denoted by the predicate, and the predicates in [11] to [13] take the progressive. However, 'feel well' does so more readily than the predicates 'resemble one's mother' and 'understand Russian', acceptable only in [12b] and [13b], with explicit indications of change ('more and more', 'better and better')... [T] he difference in the degree of semantic markedness between the progressive form of 'feel', on the one hand, and 'resemble' and 'understand Russian' on the other, would be seen [under RT] not as a difference in the degree of 'stativity' or 'dynamicness' inherent in the meanings of these verbs, but as a difference in the accessibility of contexts in which [they] as instantiated in the form of events achieve adequate contextual effects. Thus [12c] and [13c] are marginal because they require... too much processing effort on the part of the hearer to construct the assumptions necessary for the contextualisation of the utterance. (29)

(j) Ziv (1997) and Rubovitz (1997) choose relative clauses as the focus of analysis. Ziv's analysis concentrates on a particular variety of relative clauses: extraposed ones, in sentences such as (14a-b) 
(14) (a) People can get sick who do not eat well.

(b) Athletes must be quite strong who can lift such heavy weights.

Ziv's claim is that there is a systematic dependence between the propositions expressed by the constituent clauses of the sentence containing the extraposed relative clause, whereas such restriction does not hold for sentences with non-extraposed ones, and this fact is easily explainable using RT. After a characterisation of background and foreground material in terms of relevance, Ziv concludes that extraposed relative clauses convey foreground material which is striking and non-predictable, and therefore likely to yield a number of non-trivial contextual implicatures (in plain words, likely to be relevant). The attempt to underline the informative importance of that material would justify, to a certain extent, the anomalous grammatical construction in these sentences.

(k) Other analysts (Kempson 1987, 1988a, 1988b; Foster-Cohen, 1994; Smith, 1989) have approached the current generative approaches to grammar, such as Government and Binding and Minimalism, using RT. This is the case of the analysis of anaphora and the binding of pronouns by Kempson and Foster-Cohen, or the RT approach to syntactic parameters by Smith.

\section{Concluding remarks}

In this article I have reviewed different attempts to study grammatical aspects of sentences with the help of S\&W's relevance theory. In many of these studies, some grammatical points, which were regarded as problematic by traditional approaches, are now explained in a more accurate way with the greater importance given to contextual features that RT analysts usually provide. As suggested above, rather than a substitution of former views on grammar, RT overlaps succesfully with them and the outcome is a better picture of how language works. Judging by the increasing number of studies which are proposed with RT as their underlying framework, we can conclude that this approach is basically correct and appealing. It will come as no surprise that new grammatical aspects are analysed under RT in search of a better picture of how grammar works.

\section{Works Cited}

Ariel, M. "Retrieving Propositions from Context: Why and How." Journal of Pragmatics 12 (1988): $567-600$.

Berbeira Gardón, J.L. "Posibilidad Epistémica, Posibilidad Radical y Pertinencia." Pragmalingüística 1 (1993): 53-78.

. "Scope-Ambiguity, Modal Verbs and Quantification." Estudios Ingleses de la Universidad Complutense 4 (1996a): 53-66.

Publicaciones, 1996b. 
223-240.

"Epistemic Modality and Discourse Connectivity." Pragmalingüistica 3-4 (1997):

"Relevance and Modality." Revista Alicantina de Estudios Ingleses 11 (1998).

Bertuccelli-Papi, M. "Semantic Vagueness and Degree of Precision Verbs." Textus VII (1996): 313-332.

Blakemore, D. "Linguistic Constraints on Pragmatic Interpretation: A Reassessment of Linguistic Semantics." Behavioral and Brain Sciences 10 (1987a): 712-713. Semantic Constraints on Relevance. Oxford: Blackwell, $1987 \mathrm{~b}$.

"'So' as a Constraint on Relevance." Mental Representations: The Interface between

Language and Reality. Ed. R.M. Kempson. Cambridge: Cambridge University Press, 1988a, $28-51$.

."The Organization of Discourse." Linguistics: The Cambridge Survey. Vol 4. Ed.

F. Newmeyer. Cambridge: Cambridge University Press, 1988b, 229-250.

. "Denial and Contrast: A Relevance Theoretic Analysis of But." Linguistics and

Philosophy 12 (1989): 15-37.

. "Constraints on Interpretation." Proceedings of the 16th Annual Meeting of the

Berkeley Linguistics Society, 1990, 363-370.

Understanding Utterances. Oxford: Blackwell, 1992.

Blass, R. Discourse Connectivity and Constraints on Relevance in Sissala. Ph.D. Thesis. University of London, 1988.

. Relevance Relations in Discourse. Cambridge: Cambridge University Press, 1990. "Are There Logical Relations in a Text?" Lingua 90 (1993): 91-110.

Breheny, R. "A Unitary Approach to the Interpretation of Definites." UCL Working Papers in Linguistics 9 (1997): 1-27.

Brockway, D. "Semantic Constraints on Relevance." Possibilities and Limitations of Pragmatics.

Eds. H. Parret, M. Sbisà and J. Verschueren. Amsterdam: John Benjamins, 1981, 57-77.

."Connecteurs Pragmatiques et Principle de Pertinence." Langages 67 (1982): 7-22.

Carretero Lapeyre, M. "The Relevance of Politeness in the Epistemic Interpretation of the English Modals." Pragmalinguiística 3-4 (1997): 241-259.

Carston, R. "Implicature, Explicature, and Truth-Theoretic Semantics." Mental Representations:

The Interface between Language and Reality. Ed. R.M. Kempson. Cambridge: Cambridge

University Press, 1988, 155-181.

"Conjunction, Explanation and Relevance." Lingua 90 (1993): 27-48.

"Metalinguistic Negation and Echoic Use." UCL Working Papers in Linguistics 6

(1994): 321-339.

Carston, R. and E.-J. Noh. "A Truth-Functional Account of Metalinguistic Negation, with

Evidence from Korean." UCL Working Papers in Linguistics 7 (1995), 1-26.

Clark, B. "Relevance and 'Pseudo-Imperatives'." Linguistics and Philosophy 16 (1993a): 79-121.

."Let and Let's: Procedural Encoding and Explicature." Lingua 90 (1993b): 173-200.

Foster-Cohen, S.H. "Exploring the Boundary between Syntax and Pragmatics: Relevance and the Binding of Pronouns. " Journal of Child Language 21 (1994): 237-255.

. "If You'd Like to Burn your Mouth Feel Free': A Relevance-Theoretic Account of

Conditionals Used to Children." Proceedings of the University of Hertfordshire Relevance

Theory Workshop. Ed. M. Groefsema. Chelmsford: Peter Thomas and Associates, 1997, 140148. 
Fretheim, T. "A Pragmaticization Process Affecting Norwegian Negatives with Scalar Expressions." Proceedings of the University of Hertfordshire Relevance Theory Workshop. Ed. M. Groefsema. Chelmsford: Peter Thomas and Associates, 1997, 4-15.

Grice, H.P. "Logic and Conversation." Speech acts (Syntax and Semantics 3). Eds. P. Cole and J. Morgan. New York: Academic Press, 1975, 41-78.

Groefsema, M. "Can, May, Must and Should: A Relevance-Theoretic Account." Journal of Linguistics 31 (1995): 53-79.

Gutt, E.-A. "Towards an Analysis of Pragmatic Connectives in Silt'i'." Proceedings of the Eighth International Conference of Ethiopian Studies. 26-30 November 1984. vol. 1. Addis Ababa University: ELM Publications, 1988.

Haegeman, L. "Relevance Theory and the Scope of Grammar." Behavioral and Brain Sciences 10 (1987): 719-720.

291-319. "Be Going to and Will: A Pragmatic Account." Journal of Linguistics 25 (1989):

"The Interpretation of the Particle da in West Flemish." Lingua 90 (1993): 111-128.

Higashimori, I. "Except, But and Relevance Theory." English Literature Review 36 (1992a): 62-108.

."BUT/YET/Still and Relevance Theory." Papers Presented to Professor Yoshimitsu Narita on the Occasion of his Sixtieth Birthday. Tokyo: Eihosha, 1992b, 333-354. "A Relevance-Theoretic Analysis of EVEN, SAE/SURA/MO/TEMO/DEMO/

DATTE/MADE." English Literature Review 38 (1994): 51-80. . "Correlation of Discourse Connectives: A Relevance-Theoretic Account." English Literature Review 39 (1995): 48-88.

"EVEN, SAE/SURA/MO as Constraints on contextual Assumptions." Discourse and

Perspectives in Cognitive Linguistics (Current Issues in Linguistic Theory 151). Eds. W.-A.

Liebert, G. Redeker and L. Waugh. Amsterdam: John Benjamins, 1997, 37-59.

Ifantidou-Trouki, E. "Sentential Adverbs and Relevance." Lingua 90 (1993): 69-90.

Itani, R. "Japanese Conjunction Kedo ('But') in Utterance-Final Use: A Relevance-Based Analysis." English Linguistics 9 (1992): 265-283.

Iten, C. "Because and Although: A case of Duality?" UCL Working Papers in Linguistics 9 (1997): 55-76.

Jucker, A. "Pragmatics of the Definite Article in English." Pragmatic Grammar Components. Ed. F.J.H. Dols. Tilburg: Tilburg University Press, 1992, 117-133. "The Discourse Marker Well: A Relevance-Theoretical Account. "Journal of Pragmatics 19 (1993): 435-452.

Kempson, R. "Grammars as Input Systems." Behavioral and Brain Sciences 10 (1987): 721-722. ."On the Grammar-Cognition Interface: The Principle of Full Interpretation." Mental Representations: The Interface Between Language and Reality. Ed. R.M. Kempson. Cambridge: Cambridge University Press, 1988a, 199-224.

"Logical Form: The Grammar-Cognition Interface." Journal of Linguistics 24 (1988b): 393-431.

Klinge, A. "The English Modal Auxiliaries: From Lexical Semantics to Utterance Interpretation." Journal of Linguistics 29 (1993): 315-357.

Lunn, P. "The Spanish Subjunctive and Relevance." Studies in Romance Linguistics. Eds. C. Kirschner and J. de Cesaris. Amsterdam: John Benjamins, 1989, 249-260.

Moeschler, J. "Pragmatic Connectives, Argumentative Coherence and Relevance." Argumentation 3 (1989a): 321-339. 
Hermès, 1989b.

Modélisation du Dialogue. Représentation de L'inference Argumentative. Paris: ."Relevance and Conversation." Lingua 90 (1993a): 149-171.

"Aspects Pragmatiques de la Réference Temporelle: Indétermination, Ordre Temporel et Inférence." Languages 112 (1993b): 39-54.

Montolio Durán, E. "La teoría de la relevancia y el estudio de los conectores discursivos." Introducción a la Pragmática Lingüística. Ed. C. Fuentes Rodríguez. Sevilla: universidad de Sevilla, 1997, 27-40.

Nicolle, S. "Relevance and the Effect of Modal Auxiliaries in Logical Reasoning Tasks." The Role of Pragmatics in Contemporary Philosophy: Contributions of the Austrian Ludwig Wittgenstein Society. Vol. 2. Eds. P. Weinagartner, G. Schurz and G. Dorn. Kirchberg an Wechsel: Austrian Ludwig Wittgenstein Society, 1997, 721-727.

"A Relevance-Theoretic Account of Be Going To." Journal of Linguistics 33 (1997b): 355-377.

Noh, E.-J. "A Relevance-Theoretic Account of Metarepresentative Uses in Conditionals." $U C L$ Working Papers in Linguistics 8 (1996): 125-163.

Papafragou, A. "Modality in Language Development: A Reconsideration of the Evidence." UCL Working Papers in Linguistics 9 (1997): 77-105.

Quirk, R., Greenbaum, S., Leech, G. and J. Svartvik. A Comprehensive Grammar of the English Language. London: Longman, 1985.

Rouchota, V. "But: Contradiction and Relevance." UCL Working Papers in Linguistics 2 (1990): 441-475.

. The Semantics and Pragmatics of the Subjunctive in Modern Greek -A Relevance Theoretic Approach. Ph.D. Thesis. University of London, 1994a.

. "The Subjunctive in Modern Greek: Dividing the Labour between Semantics and Pragmatics." Journal of Modern Greek Studies 12 (1994b): 185-201.

."Discourse Connectives: What Do They Link?" UCL Working Papers in Linguistics 8 (1996): 199-212.

Rubovitz, T. "The Relevance of Relevance Theory to Syntactic Phenomena: Relevance Theory and Extraction from Relative Clauses." Proceedings of the University of Hertfordshire Relevance Theory Workshop. Ed. M. Groefsema. Chelmsford: Peter Thomas and Associates, 1997, 120-130.

Smith, N.V. "Can Pragmatics Fix Parameters?" UCL Working Papers in Linguistics 1 (1989): 169-179. (1990): 82-94.

"Observations on the Pragmatics of Tense." UCL Working Papers in Linguistics 2

Smith, N.V. and A. Smith. "A Relevance-Theoretic Account of Conditionals." Language, Speech and Mind: Essays in Honor of Victoria Fromkin. Eds. L. Hyman and C. Li. London: Routledge, 1988, 322-352.

Sperber, D., and D. Wilson. Relevance: Communication and Cognition. Oxford: Blackwell, 1986. "Précis of Relevance: Communication and Cognition." Behavioral and Brain Sciences 10 (1987): 697-754.

Strawson, P.F. "Intention and Convention in Speech Acts." 1964. Pragmatics: A Reader. Ed. S. Davis. Oxford: Oxford University Press, 1991, 290-301.

Takeuchi, M. "Conceptual and Procedural Encoding: Cause-Consequence conjunctive Particles in Japanese." UCL Working Papers in Linguistics 9 (1997): 127-148. 
Unger, C.J. "The Scope of Discourse Connectives: Implications for Discourse Organization." Forthcoming.

Watts, R.J. "Relevance in Conversational Moves: A Reappraisal of 'Well'." Studia Anglica Posnaniensia 19 (1986): 37-59.

. "A Relevance-Theoretic Approach to Commentary Pragmatic Markers: The Case of Actually, Really and Basically." Acta Linguistica Hungarica 38 (1988): 235-260.

Wilson, D. "Relevance and Understanding." Language and Understanding. Eds. G. Brown, K. Malmkjær, A. Pollit and J. Williams. Oxford: Oxford University Press, 1994, 35-58.

Wilson, D. and D. Sperber. "Mood and the Analysis of Non-Declarative Sentences." Human Agency: Language, Duty and Value. Eds. J. Dancy, J. Moravcsik and C. Taylor. Stanford, C.A.: Stanford University Press, 1988, 77-101.

Wilson, D. and D. Sperber. "Linguistic Form and Relevance." Lingua 90 (1993): 1-25.

Yoshimura, A. "The Cognitive Structure of Negation as an NPI-Licensing Condition." English Linguistics 9 (1992): 244-264.

."Pragmatic and Cognitive Aspects of Negative Polarity." Osaka University Papers in English Linguistics 1 (1993): 141-173.

Žegarac, V. "Relevance Theory and the Meaning of the English Progressive." UCL Working Papers in Linguistics 1 (1989): 19-29.

$113-143$.

"Pragmatics and Verbal Aspect." UCL Working Papers in Linguistics 2 (1990):

"Some Observations on the Pragmatics of the Progressive." Lingua 90 (1993): 201-220.

Ziv, Y. "Relevance Theory and Extraposed Relative Clauses." Proceedings of the University of Hertfordshire Relevance Theory Workshop. Ed. M. Groefsema. Chelmsford: Peter Thomas and Associates, 1997, 112-119. 